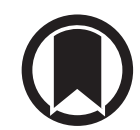

CrossMark

\title{
French multicentric validation of $A L K$ rearrangement diagnostic in 547 lung adenocarcinomas
}

Sylvie Lantuejoul ${ }^{1}$, Isabelle Rouquette ${ }^{2}$, Hélène Blons ${ }^{3}$, Nolwenn Le Stang ${ }^{4}$, Marius llie $^{5}$, Hugues Begueret ${ }^{6}$, Valerie Grégoire ${ }^{7}$, Paul Hofman ${ }^{5}$, Audrey Gros ${ }^{6}$, Stephane Garcia ${ }^{8}$, Nathalie Monhoven ${ }^{9}$, Mojgan Devouassoux-Shisheboran ${ }^{10}$, Audrey Mansuet-Lupo ${ }^{11}$, Françoise Thivolet ${ }^{12}$, Martine Antoine ${ }^{13}$, Jean-Michel Vignaud ${ }^{9}$, Frederique Penault-Llorca ${ }^{14}$, Françoise Galateau-Sallé ${ }^{4}$ and Anne McLeer-Florin ${ }^{1}$

Affiliations: ${ }^{1}$ Département d'Anatomie et de Cytologie Pathologiques, Pôle de Biologie et de Pathologie, CHU A. Michallon, and Université Joseph Fourier, INSERM U823, Institut Albert Bonniot, Grenoble, France. ${ }^{2}$ Service d'Anatomie Pathologique, Institut Universitaire du Cancer de Toulouse Oncopole, Toulouse, France. ${ }^{3}$ Département de Biologie, Hôpital Européen Georges Pompidou, Assistance Publique Hôpitaux de Paris, Université Paris Descartes, INSERM S1147, Paris, France. "Service d'Anatomie et de Cytologie Pathologiques, Registre MESONAT, CHU Côte de Nacre, U1086 INSERM-UCBN "Cancers et Préventions", Caen, France. ${ }^{5}$ Laboratoire de Pathologie Clinique et Expérimentale et Biobanque, Hôpital Pasteur, Centre HospitaloUniversitaire de Nice, Université de Nice Sophia Antipolis, Nice, France. 'Service d'Anatomie Pathologique, Service de Biologie des Tumeurs, CHU Haut-Levêque, Pessac, France. ${ }^{7}$ Institut de Pathologie, Centre de Biologie Pathologie Génétique, CHRU de Lille, Lille, France. ${ }^{8}$ Laboratoire d'Anatomie Pathologique, Hôpital Nord, Marseille, France. 'Service d'Anatomie et de Cytologie Pathologiques, Hôpital Central, Nancy, France. ${ }^{10}$ Service d'Anatomie et Cytologie Pathologiques, Hôpital de la Croix Rousse, Lyon, France. ${ }^{11}$ Service d'Anatomie et de Cytologie Pathologiques, Hôpitaux universitaire Paris centre, Paris, France. ${ }^{12}$ Service d'Anatomie et de Cytologie Pathologiques, Hôpital Louis Pradel, Bron, France. ${ }^{13}$ Service d'Anatomie et de Cytologie Pathologiques, Hôpital Tenon, Paris, France. ${ }^{14}$ Service d'Anatomie Pathologique, Centre Jean Perrin, Clermont-Ferrand, France.

Correspondence: Sylvie Lantuejoul, Dept of Pathology, Pôle de Biologie et de Pathologie, CHU A Michallon, CS 10217, 38043 Grenoble, France. E-mail: SLantuejouldachu-grenoble.fr

ABSTRACT Anaplastic lymphoma kinase $(A L K)$ gene rearrangements in lung adenocarcinoma result in kinase activity targetable by crizotinib. Although fluorescence in situ hybridisation (FISH) is the reference diagnostic technique, immunohistochemistry (IHC) could be useful for pre-screening.

Diagnostic yields of ALK IHC, FISH and quantitative reverse transcriptase PCR performed in 14 French pathology/molecular genetics platforms were compared. 547 lung adenocarcinoma specimens were analysed using 5A4 and D5F3 antibodies, two break-apart FISH probes and TaqMan kits. Clinicopathological data were recorded.

140 tumours were $A L K$ rearranged (FISH with $\geqslant 15 \%$ of rearranged cells) and 400 were $A L K$ FISH negative $(<15 \%)$. FISH was not interpretable for seven cases. $A L K$ patients were young $(\mathrm{p}=0.003)$, mostly females $(p=0.007)$ and light/nonsmokers $(p<0.0001) .13$ cases were IHC negative but FISH $\geqslant 15 \%$, including six cases with FISH between $15 \%$ and 20\%; eight were IHC positive with FISH between $10 \%$ and $14 \%$. Sensitivity and specificity for $5 \mathrm{~A} 4$ and $\mathrm{D} 5 \mathrm{~F} 3$ were $87 \%$ and $92 \%$, and $89 \%$ and $76 \%$, respectively. False-negative IHC, observed in $2.4 \%$ of cases, dropped to $1.3 \%$ for FISH $>20 \%$. Variants were undetected in $36 \%$ of ALK tumours.

Discordances predominated with FISH ranging from $10 \%$ to $20 \%$ of rearranged cells and were centre dependent. IHC remains a reliable pre-screening method for $A L K$ rearrangement detection.

@ERSpublications

IHC is useful in pre-screening for $A L K$ rearrangement, with FISH for confirmation of diagnosis http://ow.ly/Iuu5j

This article has supplementary material available from erj.ersjournals.com

Received: June 302014 | Accepted after revision: Jan 062015 | First published online: April 302015

Support statement: This study was supported by an unrestricted grant from Pfizer. Funding information for this article has been deposited with FundRef.

Conflict of interest: Disclosures can be found alongside the online version of this article at erj.ersjournals.com

Copyright @ERS 2015 


\section{Introduction}

Lung cancer is the leading cause of death by cancer worldwide, and its prognosis remains dramatically poor, only $15 \%$ of lung tumours being resectable at the time of diagnosis. Radiotherapy and chemotherapy with conventional cytotoxic agents were the only alternative until the recent discovery of "driver" oncogenic mutations and corresponding targeted therapies with encouraging results. Besides inhibition of epidermal growth factor receptor (EGFR) by gefitinib and erlotinib, crizotinib, an anaplastic lymphoma kinase (ALK)/Met small molecule inhibitor, has given good clinical responses and has been approved by the US Food and Drug Administration (FDA). Initially reported in 2007 by SoDA et al. [1], translocations involving the $A L K(2 \mathrm{p} 23)$ and the echinoderm microtubule-associated protein-like 4 (EML4) (2p21) genes are detected in $2-7 \%$ of lung adenocarcinomas and are responsible for a constant and additive ALK-enhanced kinase activity favouring proliferation, changes in cytoskeleton, migration and survival [2, 3]. ALK rearrangements are mutually exclusive with EGFR and KRAS mutations and multiple EML4-ALK variants have been described, all involving exon 20 of the $A L K$ gene. The most common are variants E13; A20 (variant 1) and E6a/b;A20 (variant 3a/b), observed in $33 \%$ and $29 \%$ of patients, respectively [4]. Other partners than EML4, such as TRK-fused gene (TFG), kinesin family member 5B (KIF5B) or kinesin light chain 1 (KLC1), have been reported [5,6]. Patients with $A L K$-rearranged tumours are overall younger than other patients with lung cancer, females, never- or light smokers $(<10$ pack-years) [6] and with advanced stage tumours. In the vast majority of cases, tumours are adenocarcinomas with solid or acinar architecture and numerous signet ring mucinous cells $[7,8]$.

Fluorescence in situ hybridisation (FISH) is the reference technique to confirm an $A L K$ rearrangement, and crizotinib was thus FDA-approved in the USA, with ALK break-apart FISH as companion diagnostic test. However, this technique remains time and cost consuming and several testing algorithms have been proposed worldwide [9-14], favouring a large-scale pre-screening by immunohistochemistry (IHC) [7, 1517]. The purpose of this study was to compare IHC using 5A4 and D5F3 antibodies (Abs) with break-apart FISH and quantitative reverse transcriptase PCR (qRT-PCR), in a series of 547 surgical specimens collected from 14 French thoracic pathology departments and Institut National du Cancer (INCa) hospital molecular genetics platforms. The aim of this study was clearly not to perform an epidemiological analysis of $A L K$ rearrangement incidence but to provide a comparison of the yields of the three techniques available and to evaluate the capacity of 14 French INCa platforms to perform $A L K$ testing.

\section{Material and methods}

From March 2012 to September 2013, 547 formalin-fixed and paraffin-embedded surgical specimens were collected from 14 thoracic pathology departments and INCa hospital molecular genetics platforms. 13 centres (centres 1-13) were in charge of IHC and FISH, two of IHC, FISH and qRT-PCR, and one of qRT-PCR only (centre 14). Each centre had to collect around 50 cases within 1 year. Only large specimens were included, in order to have enough material to perform and to compare all three techniques. In addition, inclusion of $A L K$-rearranged cases was highly favoured to reach statistical significance for comparison of the three techniques. Specimens were lung resections, lymph nodes, pleural and pericardial biopsies, as well as adrenal glands, skin, brain or liver metastases surgically biopsied or resected.

\section{Clinical and histological data}

For all cases, sex, age, tobacco history, stage and type of specimen were documented. Histological patterns according to the 2011 International Association for the Study of Lung Cancer/American Thoracic Society/ European Respiratory Society classification of lung adenocarcinomas [18] were recorded, as well as the presence of cribriform areas and signet ring cells. Thyroid transcription factor (TTF)1 and P63 expressions, scored by the product of the percentage of positive cells and the staining intensity (ranging from $1+$ to $3+$ ) were also evaluated. A staining was considered as positive when $\geqslant 10 \%$ of the cells were stained.

IHC

Depending on local protocols on different autostainers, two monoclonal $\mathrm{Ab}(\mathrm{mAb})$ clones raised against the ALK fusion protein were tested by the centres on their own cases: the 5A4 mouse mAb (from three suppliers: Abcam, Cambridge, UK; Novocastra, Burlingame, CA, USA; and Clinisciences, Nanterre, France) (tested by all centres) and the D5F3 rabbit mAb (Ventana Medical Systems Inc., Tucson, AZ, USA) (tested by all centres except centres 2, 7, 8 and 10). Three types of autostainers were used (Ventana Medical Systems Inc.; Agilent Technology Dako Denmark, Glostrup, Denmark; Menarini Diagnostic, Florence, Italy). For the D5F3 Ab, two detection kits were used: the Optiview kit for centres 1, 3, 4, 11 and 13 ; and the Ultraview kit for the other centres.

The staining pattern (membranous, cytoplasmic, or membranous and cytoplasmic) was recorded; staining was considered as positive when $\geqslant 10 \%$ of the cells were stained with a $1+$ intensity. Two staining scores were proposed and compared, one (classic score) resulting from the product of the percentage of positive 
cells and the intensity (ranging from $1+$ to $3+)$ and the other ( $\mathrm{H}$-score) defined as $1 \times(\%$ cells $1+)+2 \times(\%$ cells $2+)+3 \times(\%$ cells $3+)$.

\section{FISH}

Two alternative break-apart probes were used for this study, depending on the experience of each centre: the Vysis LSI ALK Dual colour Break Apart rearrangement probe (Abbott Molecular, Rungis, France) was used for $82 \%$ of the cases and the DAKO ALK FISH DNA Probe, Split Signal (Dako, Glostrup, Denmark) for the others. The quality of the hybridisation, the total number of malignant nuclei analysed, the percentage of each fusion $(\mathrm{F})$, the number of green $(\mathrm{G})$ and red $(\mathrm{R})$ signals observed $(1 \mathrm{~F}, 2 \mathrm{~F}, 3 \mathrm{~F}, 6 \mathrm{~F}, 1 \mathrm{R} 1 \mathrm{G} 1 \mathrm{~F}, \mathrm{xRxGxF})$ and the percentage of rearranged nuclei were recorded. An $A L K$ rearrangement was diagnosed when $\geqslant 15 \%$ of the nuclei harboured either a split pattern with $3^{\prime}$ and $5^{\prime}$ signals separated by a distance superior to the diameter of the largest signal, or isolated 3' (red) signals [19]. The distance of more than the diameter of the largest signal was chosen in order to take into account the fact that two commercial $A L K$ break-apart probe kits were used, as well as various types of epifluorescence microscopes and FISH scanning systems.

$q R T-P C R$

Three reference centres were in charge of the qRT-PCR (centres 2, 4 and 14). EML4-ALK TaqMan gene expression assays (Fisher Life Technologies, Paisley, UK) were used for the detection of V1, V3a/b, V2 E17; A20, V5 and V7 (Hs03654558, Hs03654556, Hs03654557 Hs03654560, Hs03654559), as well as for RPL13A, which was used as the reference (control) gene. The percentage of malignant cells, extracted RNA concentration, type of variant, cycle threshold $(\mathrm{Ct})$ of the reference gene and of the variant were recorded. Mutational data regarding EGFR, KRAS, HER2, BRAF and PI3KC were also recorded when available.

\section{Statistical analysis}

The comparison tests used were, for the qualitative data, the Chi-squared test and, for the quantitative data, the ANOVA test. The sensitivity, specificity, false positivity and false negativity of IHC versus the FISH technique were calculated with a $95 \%$ confidence interval. The sensitivity was the number of IHC-positive cases among the FISH-positive cases; the specificity was the number of IHC-negative cases among the FISH-negative cases. The false negativity was the number of IHC-negative and FISH-positive cases among the overall population, and the false positivity was the number of IHC-positive and FISH-negative cases among the overall population.

\section{Results}

Among the 547 cases studied, seven (1.3\%) cases were not interpretable by FISH, 140 (26\%) were ALK FISH-positive, with $\geqslant 15 \%$ of rearranged cells, and 400 (73\%) were $A L K$-negative by FISH, with $<15 \%$ of rearranged cells. For 25 cases, the percentage of positive cells was close to the positivity threshold commonly used (15\%): in 12 cases, the percentage of positive cells ranged from $10 \%$ to $14 \%$, and in 13 other cases, the percentage of positive cells ranged from $15 \%$ to $20 \%$ (table 1).

\section{ALK FISH-positive cases}

For the $140 A L K$-positive patients (positivity threshold $\geqslant 15 \%$ ), the mean age was 62 years, and there was a female predominance (77 (55\%) females versus 63 (45\%) males). 31 (22\%) were former or current smokers with a mean tobacco consumption of 40 pack-years, $11(8 \%)$ were light smokers ( $\leqslant 15$ pack-years) and 64 (46\%) were nonsmokers; tobacco habit was unknown for $34(24 \%)$ patients. Overall, $70 \%$ of the $A L K$-positive patients for whom the tobacco habit was documented were light or nonsmokers. 28 (20\%) were at stages I and II at the time of diagnosis and 77 (55\%) were at advanced stages (III and IV) (data unknown for 35 patients) (table 2).

TABLE 1 Summary of the anaplastic lymphoma kinase $(A L K)$ fluorescence in situ hybridisation (FISH) and immunohistochemistry (IHC) results

\begin{tabular}{lcccccc} 
& FISH NI & \multicolumn{3}{c}{ ALK FISH rearranged tumour cells \% } & \multirow{2}{*}{ Total } \\
\cline { 3 - 5 } & & $<\mathbf{1 0}$ & $\mathbf{1 0 - 1 4}$ & $\mathbf{1 5 - 2 0}$ & $\mathbf{2 0}$ & \\
\hline Total & 7 & 388 & 12 & 13 & 127 & 547 \\
ALK IHC positive\# & $2(29)$ & $100(26)$ & $8(67)$ & $7(54)$ & $120(94)$ & $237(43)$ \\
ALK IHC negative & $5(71)$ & $288(74)$ & $4(33)$ & $6(46)$ & $7(6)$ & $310(57)$
\end{tabular}

Data are presented as $\mathrm{n}$ or $\mathrm{n}(\%)$. NI: not interpretable. ${ }^{\#}$ : expression in $>10 \%$ of tumour cells. 
TABLE 2 Clinical data concerning anaplastic lymphoma kinase (ALK) fluorescence in situ hybridisation (FISH)-positive and FISH-negative patients

\begin{tabular}{|c|c|c|c|}
\hline & $\begin{array}{l}A L K \text { FISH-positive } \\
\text { patients }^{\#}\end{array}$ & $\begin{array}{l}A L K \text { FISH-negative } \\
\text { patients }{ }^{\Uparrow}\end{array}$ & p-value \\
\hline Patients & 140 & 400 & \\
\hline Age yrs & $62(17-86)$ & $63(30-90)$ & 0.003 \\
\hline Sex & & & 0.007 \\
\hline Males & $63(45)$ & $233(58)$ & \\
\hline Females & $77(55)$ & $167(42)$ & \\
\hline Tobacco habit & & & $<0.0001$ \\
\hline Former and current smokers & 22 and $9(22)^{\S}$ & 129 and $71(50)^{\S}$ & \\
\hline Nonsmokers & $64(46)$ & 72 (18) & \\
\hline Light smokers $^{+}$ & $11(8)$ & $24(6)$ & \\
\hline Not available & $34(24)$ & $104(26)$ & \\
\hline $\begin{array}{l}\text { Tobacco consumption of former and } \\
\text { current smokers pack-years }\end{array}$ & $40(18-60)$ & $40(18-160)$ & 0.15 \\
\hline Stages & & & 0.003 \\
\hline $\mid A$ & $10(7)$ & $45(11)$ & \\
\hline IB & $5(4)$ & $43(11)$ & \\
\hline$\| \mathrm{A}$ & $9(6)$ & $33(8)$ & \\
\hline IIB & $4(3)$ & $25(6)$ & \\
\hline IIIA & 19 (13) & $68(17)$ & \\
\hline IIIB & $5(4)$ & $16(4)$ & \\
\hline IV & $53(38)$ & $90(23)$ & \\
\hline Not available & $35(25)$ & $80(20)$ & \\
\hline
\end{tabular}

Data are presented as $n$, mean (range) or $n(\%)$, unless otherwise stated. ${ }^{*}: \geqslant 15 \%$ of rearranged cells;

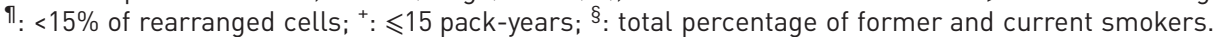

Specimens were mainly (52\%) surgical biopsies, with surgical resections representing $41 \%$. The specimens came mostly from the lung $(52 \%)$, lymph node $(27 \%)$ and pleura $(13 \%)$, the remainder from brain $(n=3$; $2 \%)$, skin and soft tissues $(n=2 ; 1.5 \%)$ and liver $(n=1 ; 1 \%)$. The mean (range) percentage of malignant cells was $60 \%(10-100 \%)$ (table 3$)$.

At histology, $A L K$-positive adenocarcinomas were predominantly (representing $\geqslant 50 \%$ of the tumour) solid in $46 \%$ of the cases, acinar in $36 \%$, papillary in $12 \%$, lepidic in $6 \%$ and micropapillary in $4 \%$. Cribriform

\begin{tabular}{|c|c|c|c|}
\hline & $A L K$-positive tumours & $A L K$-negative tumours & p-value \\
\hline Specimens & 140 & 400 & \\
\hline Type of specimen & & & $<0.0001$ \\
\hline Surgical biopsies & 73 (52) & $71(18)$ & \\
\hline Surgical resections & $57(41)$ & $291(73)$ & \\
\hline Data not available & $10(7)$ & $36(9)$ & \\
\hline Cell blocks & 0 & $2(<1)$ & \\
\hline \multicolumn{4}{|l|}{ Sites } \\
\hline Lung & 72 (51.5) & $284(71)$ & $<0.0001$ \\
\hline Lymph node & $38(27)$ & $41(10)$ & $<0.0001$ \\
\hline Pleura & $18(13)$ & $36(9)$ & 0.19 \\
\hline Brain & $3(2)$ & $22(6)$ & 0.10 \\
\hline Bone & 0 & $2(0.5)$ & NS \\
\hline Liver & $1(1)$ & 0 & NS \\
\hline Pericardium & 0 & $2(0.5)$ & NS \\
\hline Skin and soft tissues & $2(1.5)$ & $2(0.5)$ & NS \\
\hline Adrenal gland & 0 & $2(0.5)$ & NS \\
\hline Not available & $6(4)$ & $9(2)$ & NS \\
\hline Malignant cells \% & $60(10-100)$ & $60(5-100)$ & 0.89 \\
\hline
\end{tabular}

Data are presented as n, $\mathrm{n}(\%)$ or mean (range), unless otherwise stated. NS: nonsignificant. 
areas, representing $\geqslant 10 \%$ of the tumour, were observed in $19 \%$ of the cases. Presence of signet ring cells was noted in $29(21 \%)$ of the cases. TTF1 expression involving $\geqslant 10 \%$ of the tumour cells was observed in $93 \%$ of the tumours, with a mean percentage of positive cells of $93 \%$ and a mean staining intensity of 2.5 . P63 expression involving $\geqslant 10 \%$ of the tumour cells was observed in $39 \%$ of the tumours, with a mean percentage of positive cells of $50 \%$ and a mean staining intensity of 2 (table 4 ).

ALK IHC expression was observed in 127 (91\%) out of 140 FISH-positive cases (see section on discordant cases for details of seven FISH-positive/IHC-negative cases), involving $87 \%$ and $92 \%$ of the cells, with mean staining intensities of 2.3 and 2.6 with 5A4 and D5F3 mAbs, respectively (table 5). The mean classic score was 213 and the $\mathrm{H}$-score was 211 for $5 \mathrm{~A} 4 \mathrm{mAb}$, and the mean classic score was 255 and the $\mathrm{H}$-score was 256 for D5F3 mAb. A cytoplasmic and membranous staining was observed in 58 cases, and cytoplasmic-only staining was observed in the others. At least four cases were negative with 5A4 but positive with D5F3 (involving $20-100 \%$ of the cells with staining intensities from $1+$ to $3+$ ) and seven cases were negative with D5F3 but positive with $5 \mathrm{~A} 4$ (with $30-100 \%$ of the cells harbouring a staining intensity from $1+$ to $3+$ ) (fig. 1).

Regarding FISH, a mean of 90 tumour cell nuclei were analysed and the mean (range) percentage of rearranged cells was $63 \%(21-100 \%)$ (table 5). In 58\% of the cases, the predominant rearrangement pattern observed was $\mathrm{xRGxF}$, and in $36 \%$ it was $1 \mathrm{R} 1 \mathrm{G} 1 \mathrm{~F}$.

Concerning qRT-PCR, the mean concentration of RNA extracted was $139 \mathrm{ng} \cdot \mu \mathrm{L}^{-1}$, the mean Ct for the $A L K$ variant detected was 35, and the mean Ct for the reference gene was 26 (table 5). For 50 (36\%) cases no variant was detected, $33(24 \%)$ cases harboured a variant 1 (one case presenting a combination of variants 1, 2 and 3a/b), 29 (21\%) cases harboured a variant 3a/b (one in association with a variant 7), nine $(6 \%)$ cases presented a variant 2 , three $(2 \%)$ cases a variant 5 , five $(4 \%)$ cases were not interpretable and for $14(10 \%)$ cases data were not available. Regarding the distribution of qRT-PCR data, there was a centre effect, illustrated by figure 2 .

Among the 99 cases for which the mutational profile was recorded, only one case presented a KRAS mutation (see online supplementary table S1).

\section{ALK FISH-negative cases}

With respect to the $400 A L K$-negative patients ( $<15 \%$ of rearranged cells), a male predominance was observed (233 (58\%) males versus 167 (42\%) females) and the mean age was 63 years (table 2). Most were smokers: 200 (50\%) were current or former smokers with a mean consumption of 40 pack-years, and 96 (24\%) were light

\begin{tabular}{|c|c|c|c|}
\hline & $A L K$-positive tumours & $A L K$-negative tumours & p-value \\
\hline Tumours & 140 & 400 & \\
\hline \multicolumn{4}{|l|}{ Predominant patterns" } \\
\hline Solid & $65(46)$ & $160(40)$ & NS \\
\hline Acinar & $51(36)$ & $167(42)$ & NS \\
\hline Papillary & $17(12)$ & $62(16)$ & NS \\
\hline Lepidic & $8(6)$ & $13(3)$ & NS \\
\hline Micropapillary & $5(4)$ & $10(3)$ & NS \\
\hline Cribriform areas" & $26(19)$ & $42(11)$ & 0.001 \\
\hline Signet ring cells ${ }^{\pi}$ & $29(21)$ & $20(5)$ & $<0.0001$ \\
\hline \multicolumn{4}{|l|}{ TTF1 expression" } \\
\hline Samples & 135 & 385 & \\
\hline TTF1-positive tumours & 125 (93) & $300(78)$ & 0.0001 \\
\hline Mean positive cells $\%$ & 93 & 80 & 0.0006 \\
\hline Mean staining intensity & 2.5 & 2.6 & NS \\
\hline \multicolumn{4}{|l|}{ P63 expression } \\
\hline Samples & 103 & 337 & \\
\hline P63-positive tumours & 40 (39) & $75(22)$ & 0.0008 \\
\hline Mean positive cells \% & 50 & 33 & 0.003 \\
\hline Mean staining intensity & 2.0 & 1.7 & 0.02 \\
\hline
\end{tabular}

Data are presented as $\mathrm{n}$ or $\mathrm{n}(\%)$, unless otherwise stated. TTF: thyroid transcription factor; NS: nonsignificant. ${ }^{\#}$ : representing $\geqslant 50 \%$ of the tumour; one tumour can present two predominant patterns if they both represent $50 \%$ of the tumour. ${ }^{\text {?: }}$ : involving $\geqslant 10 \%$ of the tumour cells. 
TABLE 5 Anaplastic lymphoma kinase (ALK) immunohistochemistry (IHC), fluorescence in situ hybridisation (FISH) and quantitative reverse transcriptase PCR (qRT-PCR) data in ALK

FISH-positive and -negative tumours

ALK FISH-positive tumours ALK FISH-negative tumours

p-value

\begin{tabular}{|c|c|c|c|}
\hline Tumours & 140 & 400 & \\
\hline \multicolumn{4}{|l|}{ IHC clone 5A4 } \\
\hline Samples & 120 & 375 & \\
\hline Mean positive cells \% & 87 & 12 & $<0.0001$ \\
\hline Mean staining intensity & 2.3 & 1.7 & $<0.0001$ \\
\hline Mean classic score & 213 & 81 & $<0.0001$ \\
\hline Mean H-score & 211 & 81 & $<0.0001$ \\
\hline \multicolumn{4}{|l|}{ IHC clone D5F3 } \\
\hline Samples & 75 & 256 & \\
\hline Mean positive cells \% & 92 & 25 & $<0.0001$ \\
\hline Mean staining intensity & 2.6 & 1.2 & $<0.0001$ \\
\hline Mean classic score & 255 & 77 & $<0.0001$ \\
\hline Mean H-score & 256 & 81 & $<0.0001$ \\
\hline \multicolumn{4}{|l|}{ FISH } \\
\hline Rearranged cells \% & $63(21-100)$ & $2(0-9)$ & $<0.0001$ \\
\hline Mean nuclei analysed & 90 & 86 & \\
\hline \multicolumn{4}{|l|}{ qRT-PCR } \\
\hline Mean RNA extracted $n g \cdot \mu L^{-1}$ & 139 & 174 & 0.06 \\
\hline$A L K$ variant $\mathrm{Ct}$ & $35(26-44)$ & $30(26.6-35)$ & 0.05 \\
\hline Reference gene Ct & $26(21-37)$ & $26(21-35)$ & NS \\
\hline No $A L K$ variant detected & $50(36)$ & 378 (95) & $<0.0001$ \\
\hline Variant 1 & $33(24)^{\#}$ & 1 & $<0.0001$ \\
\hline Variant 2 & $9(6)$ & 0 & $<0.0001$ \\
\hline Variant 3a/b & $29(21)$ & 0 & $<0.0001$ \\
\hline Variant 5 & $3(2)^{\pi}$ & 0 & 0.03 \\
\hline Variant 7 & $1(1)$ & 0 & NS \\
\hline Not available & $14(10)$ & $9(2)$ & 0.0004 \\
\hline Not interpretable & $5(4)$ & $10(2)$ & NS \\
\hline
\end{tabular}

Data are presented as $\mathrm{n}$, mean (range) or $\mathrm{n}(\%)$, unless otherwise stated. Ct: cycle threshold; $\mathrm{Ns}$ : nonsignificant. ${ }^{\#}$ : one with 2 and $3 \mathrm{a}$; ${ }^{\text {ๆ }}$ : one with $3 \mathrm{a}$ and one with $7 \mathrm{~J}$.

or nonsmokers; data were unknown for $104(26 \%)$ patients. At the time of diagnosis, 146 (37\%) were at stages I and II, and $174(43 \%)$ at stages III and IV; data were not recorded for 80 (20\%) patients.

Most $A L K$-negative specimens arose from the lung $(\mathrm{n}=284 ; 71 \%)$, lymph nodes $(\mathrm{n}=41 ; 10 \%)$ and pleura $(n=36 ; 9 \%)$; the remaining samples were brain $(n=22 ; 6 \%)$, bone $(n=2 ; 0.5 \%)$, pericardial $(n=2 ; 0.5 \%)$, skin and soft tissues $(n=2 ; 0.5 \%)$ and adrenal gland $(n=2 ; 0.5 \%)$ metastases. 291 (73\%) were surgical resections, $71(18 \%)$ were surgical biopsies and two specimens were cell blocks. The mean (range) percentage of malignant cells was 60\% (5-100\%) (table 3).

At histology, $A L K$-negative adenocarcinomas were predominantly acinar in $42 \%$ of the cases, solid in $40 \%$, papillary in 16\%, lepidic in 3\% and micropapillary in 3\%, with 37 cases containing $>5 \%$ of micropapillary areas (table 4). Cribriform areas were noticed in $11 \%$ of the cases. Signet ring cells were observed in only $5 \%$ of the cases. TTF1 expression was observed in $300(78 \%)$ cases, with a mean percentage of positive cells of $80 \%$ and a mean staining intensity of 2.6. P63 expression was observed in $75(22 \%)$ tumours, with a mean percentage of positive cells of $33 \%$ and a mean staining intensity of 1.7 .

ALK IHC expression was observed in 42 cases with the 5A4 Ab and 62 cases with the D5F3 Ab, but the mean percentages of positive cells were $12 \%$ and $25 \%$ and the mean staining intensities were 1.7 and 1.2 with 5A4 and D5F3 Abs, respectively. The mean classic and H-scores were 81 and 81 for 5A4 and 77 and 81 for D5F3 (table 5).

Regarding FISH analysis, with a mean of 86 nuclei analysed, the percentage of rearranged cells ranged from $0 \%$ to $9 \%$, with a mean of $2 \%$ (table 5 ).

For qRT-PCR, the mean amount of extracted RNA was $174 \mathrm{ng} \cdot \mu \mathrm{L}^{-1}$ and for the vast majority (95\%) of the cases, no variant was detected except for one case (variant 1), which remained both D5F3/5A4 IHC and FISH negative. For 10 cases, data were not interpretable and were not available for nine other cases (table 5). 

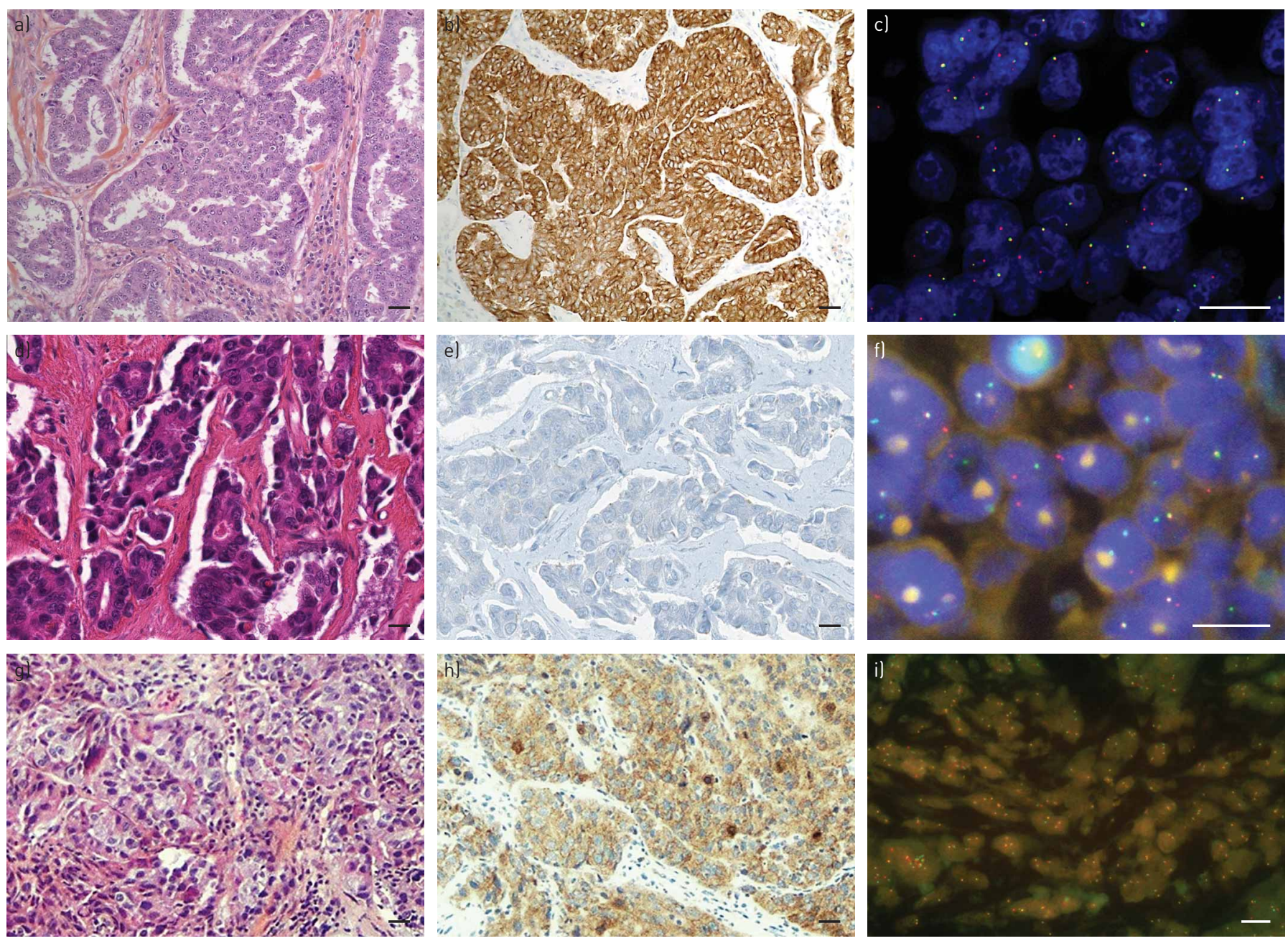

FIGURE 1 Three representative lung adenocarcinoma cases, with contiguous sections from the same tumour sample. a, d and g) Histological features visualised with haematoxylin-eosin-saffron. b, e and h) Anaplastic lymphoma kinase (ALK) immunohistochemical (IHC) staining with the 5A4 clone (immunoperoxidase). c, f and i) ALK fluorescence in situ hybridisation (FISH) signals. Tumour nuclei hybridised with the Vysis LSI ALK Dual colour Break Apart rearrangement probe (Abbott Molecular, Rungis, France). Rearranged ALK is indicated by split 3' (green) and 5' (red) signals or isolated 3' (red) signals. a-c) Sample 1, showing a) acinar pattern, b) positive ALK IHC (100\% with staining intensity $3+)$ and c) positive ALK FISH ( $>20 \%$ rearranged cells). A variant 3 was detected by qRT-PCR. d-f) Sample 2, showing d) acinar pattern, e) negative ALK IHC and f) positive FISH (>20\% rearranged cells). A variant 1 was detected by qRT-PCR. g-i) Sample 3, showing g) solid pattern, h) positive ALK IHC (100\% with staining intensity 3+) and i) borderline FISH (14\% rearranged cells). A variant 3 was detected by qRT-PCR. Scale bars: a, b, g and h) $20 \mu \mathrm{m}$; $-\mathrm{f}$ and i) $10 \mu \mathrm{m}$.
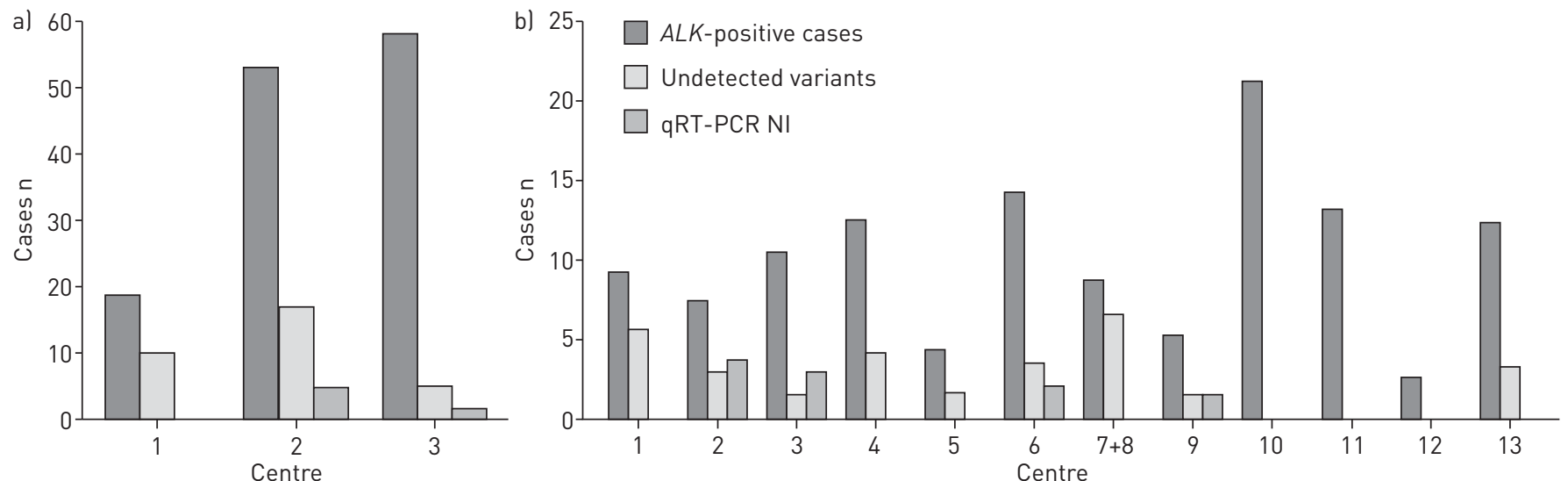

FIGURE 2 Quantitative reverse transcriptase PCR (qRT-PCR) data according to a) centres in charge of qRT-PCR and b) initial pathology centres. $A L K$ : anaplastic lymphoma kinase; NI: not interpretable. 
Among the 256 ALK-negative tumours with mutational data available, 13 (5\%) were EGFR exon 19 deleted, nine (4\%) were EGFR exon 21 mutated, 53 (22\%) were KRAS mutated, one (0.4\%) was BRAF V600E mutated, one $(0.4 \%)$ was HER2 mutated and five (2\%) were PI3KCA mutated (online supplementary table S1).

\section{Discordant cases}

25 cases presented $10-20 \%$ of rearranged tumour cells (table 6). Among the 12 cases with $10-14 \%$ of rearranged cells, eight were positive by IHC and two presented a variant 1 or 3 by qRT-PCR. Among the 13 cases with FISH ranging between $15 \%$ and $20 \%$ of rearranged cells, six cases were negative by IHC with both Abs (5A4 and D5F3); out of these, four were negative by qRT-PCR, one had a variant 1, and for one case, qRT-PCR results were not available. Seven cases with FISH showing $>20 \%$ of rearranged cells were negative by IHC; the percentages of rearranged cells were $22 \%, 30 \%, 40 \%, 54 \%, 60 \%, 70 \%$ and $92 \%$. Four (57\%) out of seven cases came from one centre, centre 10; the other three cases were distributed among centres 6, 11 and 13. Two harboured a variant 1 . Overall, among the $13 \mathrm{FISH}^{+} / \mathrm{IHC}^{-}$cases, eight (62\%) came from centre 10; the other five cases were distributed among centres 4, 6, 11 and 13 . This centre effect is illustrated by figure 3, showing the distribution of discordances according to Abs, IHC and FISH results in each centre. Online supplementary table S1 details the characteristics of patients with $A L K$ rearrangements or with discordant IHC/FISH data and their response to crizotinib when available.

\section{Statistical analysis}

Overall, statistical differences were found concerning the female predominance in $A L K$-positive patients $(\mathrm{p}=0.007)$, their younger age $(\mathrm{p}=0.003)$, their lower tobacco consumption $(\mathrm{p}<0.0001)$, advanced stages $(\mathrm{p}=0.003)$, and the distribution of specimens $(\mathrm{p}<0.0001)$. No statistical differences were observed between $A L K$-positive and -negative tumours concerning histology, with the exception of cribriform areas and signet ring cells, which were most frequent in $A L K$-positive tumours ( $\mathrm{p}=0.001$ and $\mathrm{p}<0.0001$, respectively). TTF1 and P63 expression levels were also significantly higher in $A L K$-positive tumours ( $\mathrm{p}=0.0001$ and $\mathrm{p}=0.0008$ ).

With positivity thresholds of $10 \%$ and $15 \%$ for IHC and FISH, respectively, the 5A4 clone sensitivity was $87 \%$ (95\% CI $79-92 \%)$ and its specificity was $89 \%$ (95\% CI $85-92 \%)$. The false negativity of 5A4 IHC versus FISH was 3\% (95\% CI 1-5\%) and the false positivity was 9\% (95\% CI 6-11\%). D5F3 clone sensitivity was $92 \%$ (95\% CI $83-97 \%)$ and its specificity was $76 \%$ (95\% CI 70-82\%); false negativity of D5F3 IHC versus FISH was 2\% (95\% CI 0-4\%) and false positivity was $18 \%$ (95\% CI 14-23\%). Overall, by combining the data obtained with the two Abs, the false negativity of IHC versus FISH was $2.4 \%$ and the false positivity was $20 \%$. However, if the cases with FISH ranging from $10 \%$ to $20 \%$ were not taken into account, the false negativity of IHC would drop to $1.3 \%$.

\section{Discussion}

The present study is the second largest study to date on $A L K$ rearrangements in adenocarcinoma in French Caucasian patients [20]. However, our study does not reflect ALK rearrangement epidemiology or

TABLE 6 Details of all 547 cases, including discordant cases

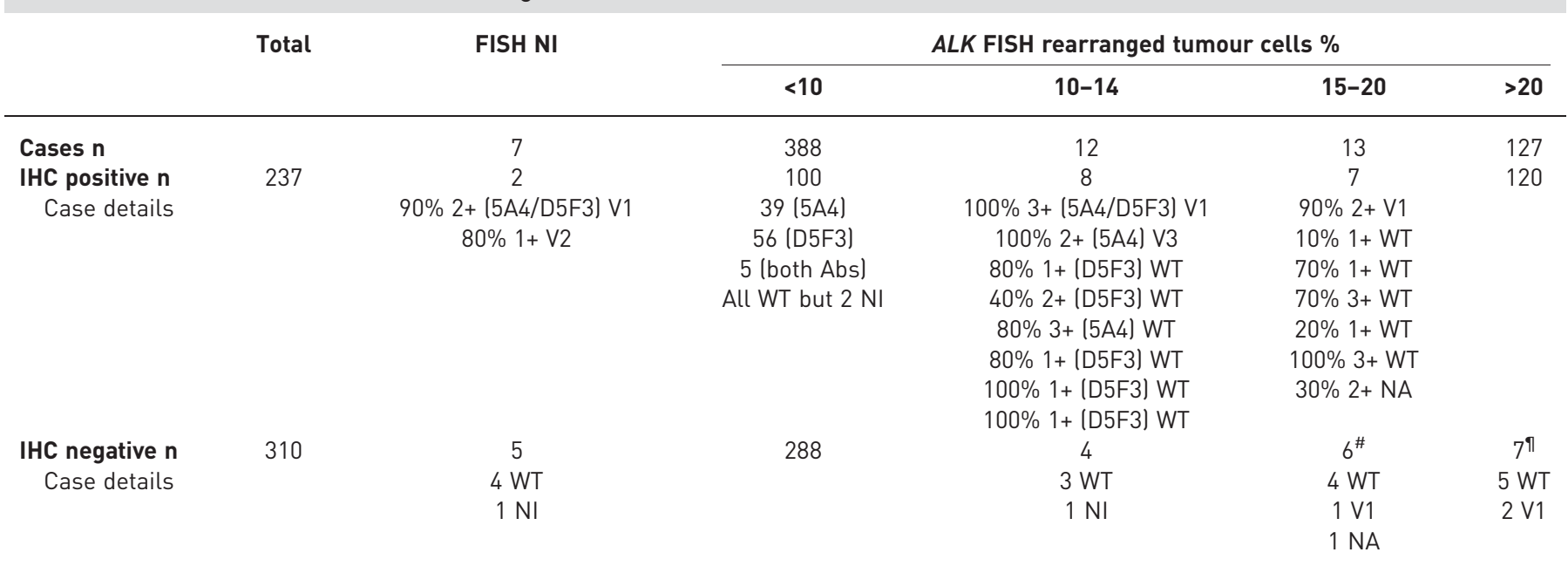

FISH: fluorescence in situ hybridisation; NI: not interpretable; ALK: anaplastic lymphoma kinase; IHC: immunohistochemistry; V: variant; WT: wild type; Abs: antibodies; NA: not available. ${ }^{\#}$ : four cases from centre 10, one from centre 6, one from centre 4. " : four cases from centre 10 , three cases from centres 6,11 and 13 ; the percentages of rearranged cells were $22 \%, 30 \%, 40 \%, 54 \%, 60 \%, 70 \%$ and $92 \%$. 

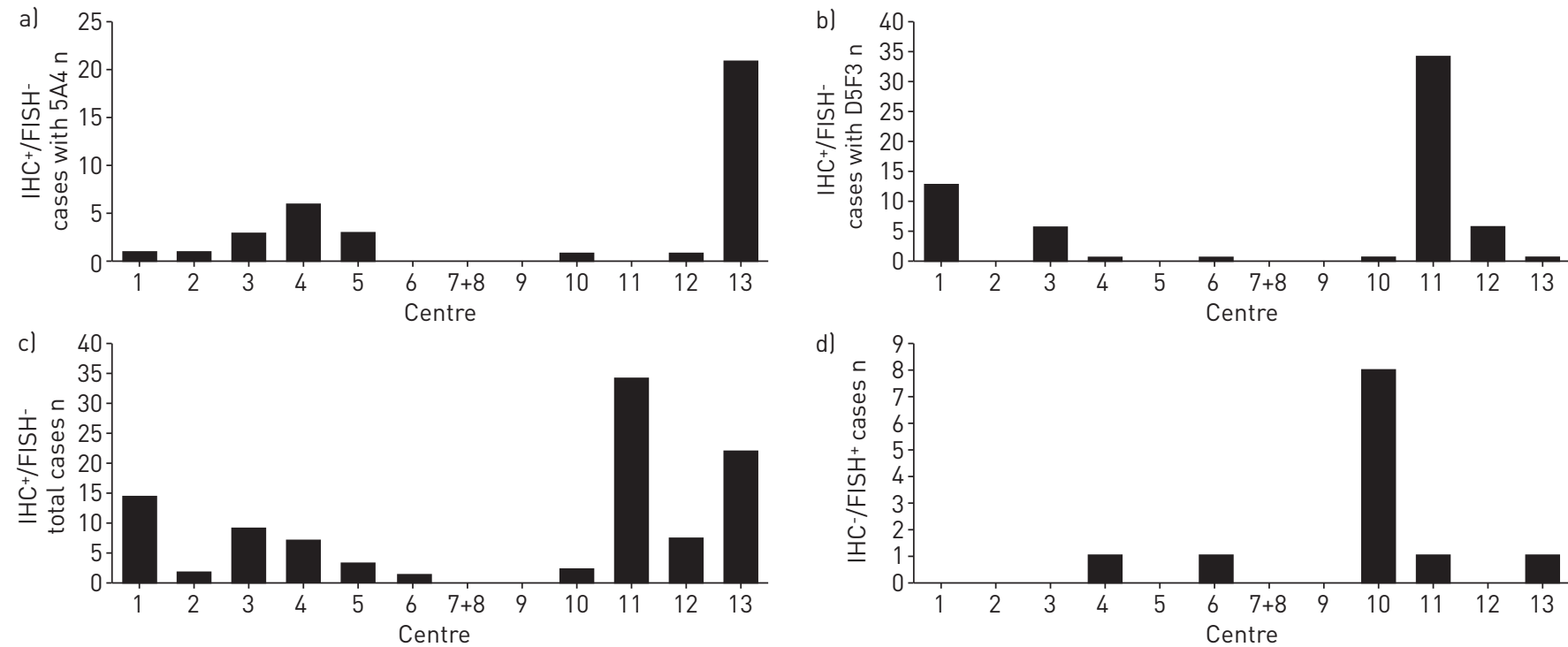

FIGURE 3 Distribution among the 13 participating centres of cases that had discordant results for immunohistochemistry (IHC) and fluorescence in situ hybridisation (FISH). IHC-positive/FISH-negative cases according to IHC with a) 5A4 and b) D5F3 antibodies. c) Total IHC-positive/FISH-negative cases. d) IHC-negative/FISH-positive cases.

the routine practice of INCa molecular genetics platforms, as the aims of this study were only to evaluate the yield of the three techniques used for $A L K$ rearrangement detection and to evaluate the capacity of several platforms to perform $A L K$ testing using their own protocols and equipment. 14 thoracic expert pathologists and molecular biologists working in pathology departments and molecular genetics platforms all over the French territory analysed 547 lung adenocarcinoma surgical specimens using ALK IHC and FISH. qRT-PCR analyses were also performed concomitantly by three experienced laboratories. Our series was deliberately enriched in $A L K$-rearranged cases and surgical specimens, in order to have enough material to compare the three techniques and to limit the number of small specimens. We emphasise the role of IHC as a pre-screening method to detect ALK rearrangement, and demonstrated that FISH needs to be rigorously and homogeneously assessed and interpreted, particularly in borderline cases harbouring $10-20 \%$ of rearranged cells.

We confirm herein the literature regarding the $A L K$-positive population [6, 7, 21-23], $A L K$ patients being younger than the other lung cancer patients, most frequently women and non- or light smokers. However, $22 \%$ of our cases were previous or current smokers, with one patient smoking 60 pack-years, confirming that smoking habit is not a reliable criterion to predict or to exclude $A L K$ rearrangement. Our patients more frequently presented at advanced stages than $A L K$-negative patients, but our series is biased as the majority of surgical specimens were lung resections, performed in patients with limited disease at the time of diagnosis. We did not notice a higher number of brain or serous metastases in our series, which is again biased by our specimen selection.

Regarding histology, although $A L K$-positive tumours presented most frequently with a solid pattern, no typical pattern was associated with $A L K$ rearrangement. However, as reported previously [8], abundant cribriform and signet ring cell-rich areas, characteristic of $A L K$ tumours, were observed in nearly $20 \%$ of the tumours, but were not specific because they were also observed in 5\% of $A L K$-negative tumours. $A L K$-positive tumours were more often TTF1 positive than $A L K$-negative tumours, but some were TTF1 negative; this criterion should therefore not be used to select adenocarcinomas to be tested by FISH. $A L K$-positive tumours were also P63 positive, with a mean intensity of $2+$, but again this was not specific. Unfortunately, we did not assess P40 expression, this protein being reported to be more specific than P63 for squamous differentiation, and we did not test our $A L K$-positive tumours regarding P63 amplification.

127 out of 140 ALK FISH-positive tumours were frankly positive by IHC either with 5A4 or D5F3 Abs, and we did not see any differences using the classic or the $\mathrm{H}$-scores for both Abs. Among the 389 ALK-negative tumours with $<10 \%$ of rearranged cells by FISH, 95 also stained with $5 \mathrm{~A} 4$ or D5F3 Abs, with $12-25 \%$ of positive cells with intensities between $1+$ and $2+$. The two Abs used showed comparable sensitivity and specificity, even if D5F3 was slightly less specific but more sensitive. A background staining with $\mathrm{D} 5 \mathrm{~F} 3 \mathrm{Ab}$ has been reported by the manufacturers, probably related to the tyramine amplification used by several centres, which indeed exhibited the highest ratios of false positivity. However, we should 


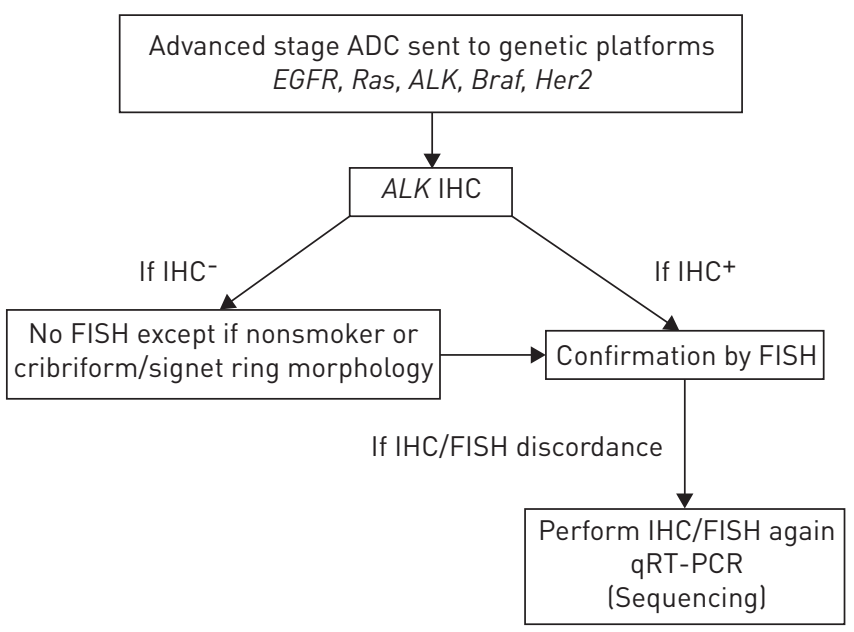

FIGURE 4 Anaplastic lymphoma kinase $(A L K)$ testing algorithm. ADC: adenocarcinoma; EGFR: epidermal growth factor receptor; IHC: immunohistochemistry; FISH: fluorescence in situ hybridisation; qRT-PCR: quantitative reverse transcriptase PCR.

point out that our study was conducted at the beginning of D5F3 commercialisation and pathologists are now aware not to take into account nonspecific mucus staining. At the same time, one could argue that there was no prejudice for overdiagnosis of cases by IHC in a screening strategy, when rearrangements are further confirmed by FISH, and there is also growing evidence in the literature that some $A L K$ IHC-positive but FISH-negative tumours can be successively treated by crizotinib. For instance, in 2014, a case only positive by IHC demonstrated a very peculiar rearrangement with very small insertions, which could not be detected by FISH but were revealed by sequencing [24]. Only seven cases were not interpretable by FISH, whereas up to $20 \%$ of FISH failures are reported in the literature, due to technical problems and sample limitation. By studying only surgical specimens containing an average of $60 \%$ of tumour cells, we therefore limited the number of non-interpretable FISH for sample issues. For all cases, a mean number of 90 cells were analysed by FISH, in agreement with CAMIDGE et al. [19] recommending the analysis of a minimum of 60 cells.

Regarding the $140 A L K$-rearranged tumours with $\geqslant 15 \%$ rearranged cells, only 13 were not positive by IHC. This represents $2.4 \%$ of the cases, $1.3 \%$ if borderline FISH between $15 \%$ and $20 \%$ are not taken into account. Eight $(62 \%)$ cases out of $13 \mathrm{FISH}^{+} / \mathrm{IHC}^{-}$came from the same centre. For two of these $\mathrm{FISH}^{+} / \mathrm{IHC}^{-}$cases, presence of variant 1 was identified by qRT-PCR. Overall, our discordance rate is far from that reported by Cabillic et al. [20]. This previous study, based on the daily practice of two French molecular genetics platforms, reported a very low rate of positive cases by both FISH and IHC (80 (53\%) out of 150), reaching $59 \%$ ( 80 out of 135) if noncontributive cases were excluded. In this study, the authors reported 36 discordant FISH-positive and IHC-negative cases among the 3244 cases analysed concomitantly by the two techniques. However, by looking carefully at this study, $11 \mathrm{ALK} \mathrm{FISH}{ }^{+} / \mathrm{IHC}^{-}$cases ( $7 \%$ of the $150 \mathrm{FISH}$-positive cases) were also mutated for EGFR and KRAS genes, whereas none of the $\mathrm{FISH}^{+} / \mathrm{IHC}^{+}$cases were co-mutated for these genes. $7 \%$ is a very high and thus questionable rate, never reported in the literature before. By comparison, in our multicentric series we found only one case out of 140 that harboured a KRAS mutation concomitant with an $A L K$ rearrangement. Another questionable point in the study by CABILLIC et al. [20] is the high number of $\mathrm{FISH}^{+} / \mathrm{IHC}^{-}$cases harbouring $15-20 \%$ of rearranged cells by FISH, particularly in one

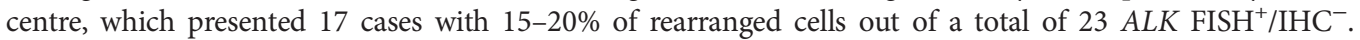
Overall, CABILLic et al. [20] reported 34 (23\%) FISH-positive tumours with a FISH ranging from 15\% to $20 \%$ out of 150 FISH-positive tumours, whereas we found only six (4\%) such cases out of 140.

Because of these discordances, although the threshold of $15 \%$ of rearranged cells has been clearly demonstrated to be clinically significant by CAMIDGE et al. [19], we have also separately analysed tumours with FISH data ranging from $10-14 \%$ and from 15-20\%. In our study, among the 13 cases presenting 15$20 \%$ of rearranged cells by FISH, seven were IHC positive and six were IHC negative, and among the 12 cases with $10-14 \%$ of rearranged cells by FISH, eight were IHC positive and four were negative; this means that most discordances occur in this borderline area of $10-20 \%$ of rearranged cells by FISH, and we must check such results and carefully weigh our conclusions. In addition, as in the study by CABILLIC et al. [20], we also observed a "centre effect" concerning the distribution of our discordant cases, one centre presenting eight of the $13 \mathrm{FISH}^{+} / \mathrm{IHC}^{-}$cases, thus gathering $62 \%$ of the discordances. 
Unfortunately, in our "borderline" or discordant cases, qRT-PCR was not discriminatory. Overall, qRT-PCR with $\leqslant 36 \%$ of cases with no variant detected was not convincing for ALK diagnosis in routine cases and did not help in discordant cases. This low rate of variant detection could be due to rare variants of EML4-ALK rearrangement not detected by the primers used, or to rare translocations involving genes other than EML4. It could also be related to the poor quality of some specimens and of the RNA extracted from formalin-fixed and paraffin-embedded tissues, even though we decided to analyse only surgical specimens with enough tumour material, leading to the extraction of $140-175 \mathrm{ng} \cdot \mu \mathrm{L}^{-1}$ of $\mathrm{RNA}$ per specimen. When detected, most variants were 1 and $3 \mathrm{a} / \mathrm{b}$, as reported in the literature, the others being variants 2 (nine cases), 5 (three cases) and 7 (one case); two cases harboured two or three variants. This finding has not been reported to date and needs to be confirmed in other larger series. As only one case of variant 1 was reported in an otherwise $A L K$-negative tumour, the specificity of this technique remains very high but its sensitivity is lower than IHC and FISH, with $36 \%$ of false-negative results. qRT-PCR was useful in rare cases with non-interpretable FISH results, confirming in two IHC-positive cases the presence of variants 1 and 2. The sensitivity of qRT-PCR was lower in our series than previously described in the literature, where only $12 \%$ of false-negative results have been reported [25] and sensitivity and specificity ranged from $94 \%$ to $100 \%$, which was comparable with IHC or FISH [25-28]. However our results differed from one laboratory to another and we also noticed a centre effect regarding qRT-PCR results.

In conclusion, our multicentric study demonstrates that the 14 French INCa molecular genetics platforms involved had comparable results, even if some discordances between the techniques and their interpretation do exist and are often centre dependent. This study still pleads for IHC pre-screening to be a routine practice, with FISH confirmation of $A L K$ rearrangement (fig. 4). Our study also reveals that, even for expert thoracic pathologists and molecular biologists, interpretation of discordant or borderline FISH and IHC data is an issue, requiring rigorous respect of guidelines and recommendations.

\section{References}

1 Soda M, Choi YL, Enomoto M, et al. Identification of the transforming EML4-ALK fusion gene in non-small-cell lung cancer. Nature 2007; 448: 561-566.

2 Horn L, Pao W. EML4-ALK: honing in on a new target in non-small-cell lung cancer. J Clin Oncol 2009; 27: 4232-4235.

3 Koivunen JP, Mermel C, Zejnullahu K, et al. EML4-ALK fusion gene and efficacy of an ALK kinase inhibitor in lung cancer. Clin Cancer Res 2008; 14: 4275-4283.

4 Sasaki T, Rodig SJ, Chirieac LR, et al. The biology and treatment of EML4-ALK non-small cell lung cancer. Eur J Cancer 2010; 46: 1773-1780.

5 Rikova K, Guo A, Zeng Q, et al. Global survey of phosphotyrosine signaling identifies oncogenic kinases in lung cancer. Cell 2007; 131: 1190-1203.

6 Shaw AT, Yeap BY, Mino-Kenudson M, et al. Clinical features and outcome of patients with non-small-cell lung cancer who harbor EML4-ALK. J Clin Oncol 2009; 27: 4247-4253.

7 Rodig SJ, Mino-Kenudson M, Dacic S, et al. Unique clinicopathologic features characterize ALK-rearranged lung adenocarcinoma in the western population. Clin Cancer Res 2009; 15: 5216-5223.

8 Yoshida A, Tsuta K, Nitta $\mathrm{H}$, et al. Bright-field dual-color chromogenic in situ hybridization for diagnosing echinoderm microtubule-associated protein-like 4-anaplastic lymphoma kinase-positive lung adenocarcinomas. J Thorac Oncol 2011; 6: 1677-1686.

9 Kim ES, Herbst RS, Wistuba II, et al. The BATTLE trial: personalizing therapy for lung cancer. Cancer Discov 2011; $1: 44-53$

10 Paik JH, Choe G, Kim H, et al. Screening of anaplastic lymphoma kinase rearrangement by immunohistochemistry in non-small cell lung cancer: correlation with fluorescence in situ hybridization. $J$ Thorac Oncol 2011; 6: 466-472.

11 Thunnissen E, Bubendorf L, Dietel M, et al. EML4-ALK testing in non-small cell carcinomas of the lung: a review with recommendations. Virchows Arch 2012; 461: 245-257.

12 Conklin CM, Craddock KJ, Have C, et al. Immunohistochemistry is a reliable screening tool for identification of ALK rearrangement in non-small-cell lung carcinoma and is antibody dependent. J Thorac Oncol 2013; 8: 45-51.

13 Marchetti A, Ardizzoni A, Papotti M, et al. Recommendations for the analysis of ALK gene rearrangements in non-small-cell lung cancer: a consensus of the Italian Association of Medical Oncology and the Italian Society of Pathology and Cytopathology. J Thorac Oncol 2013; 8: 352-358.

14 Selinger CI, Rogers TM, Russell PA, et al. Testing for ALK rearrangement in lung adenocarcinoma: a multicenter comparison of immunohistochemistry and fluorescent in situ hybridization. Mod Pathol 2013; 26: 1545-1553.

15 Inamura $\mathrm{K}$, Takeuchi $\mathrm{K}$, Togashi $\mathrm{Y}$, et al. EML4-ALK lung cancers are characterized by rare other mutations, a TTF-1 cell lineage, an acinar histology, and young onset. Mod Pathol 2009; 22: 508-515.

16 Mino-Kenudson M, Chirieac LR, Law K, et al. A novel, highly sensitive antibody allows for the routine detection of ALK-rearranged lung adenocarcinomas by standard immunohistochemistry. Clin Cancer Res 2010; 16: 1561-1571.

17 Jokoji R, Yamasaki T, Minami S, et al. Combination of morphological feature analysis and immunohistochemistry is useful for screening of EML4-ALK-positive lung adenocarcinoma. J Clin Pathol 2010; 63: 1066-1070.

18 Travis WD, Brambilla E, Noguchi M, et al. International Association for the Study of Lung Cancer/American Thoracic Society/European Respiratory Society international multidisciplinary classification of lung adenocarcinoma. J Thorac Oncol 2011; 6: 244-285.

19 Camidge DR, Kono SA, Flacco A, et al. Optimizing the detection of lung cancer patients harboring anaplastic lymphoma kinase (ALK) gene rearrangements potentially suitable for ALK inhibitor treatment. Clin Cancer Res 2010; 16: 5581-5590. 
Cabillic F, Gros A, Dugay F, et al. Parallel FISH and immunohistochemical studies of ALK status in 3244 non-small-cell lung cancers reveal major discordances. J Thorac Oncol 2014; 9: 295-306.

21 Kwak EL, Bang YJ, Camidge DR, et al. Anaplastic lymphoma kinase inhibition in non-small-cell lung cancer. $N$ Engl J Med 2010; 363: 1693-1703.

22 Bang Y, Kwak EL, Shaw AT, et al. Clinical activity of the oral ALK inhibitor PF-02341066 in ALK-positive patients with non-small cell lung cancer (NSCLC). J Clin Oncol 2010; 28: Suppl. 18, 13.

23 Shaw AT, Yeap BY, Solomon BJ, et al. Effect of crizotinib on overall survival in patients with advanced non-small-cell lung cancer harbouring ALK gene rearrangement: a retrospective analysis. Lancet Oncol 2011; 12: 1004-1012.

24 Ren S, Hirsch FR, Varella-Garcia M, et al. Atypical negative ALK break-apart FISH harboring a crizotinib-responsive ALK rearrangement in non-small-cell lung cancer. J Thorac Oncol 2014; 9: e21-e23.

25 Soda M, Isobe K, Inoue A, et al. A prospective PCR-based screening for the EML4-ALK oncogene in non-small cell lung cancer. Clin Cancer Res 2012; 18: 5682-5689.

26 Takeuchi K, Choi YL, Togashi Y, et al. KIF5B-ALK, a novel fusion oncokinase identified by an immunohistochemistry-based diagnostic system for ALK-positive lung cancer. Clin Cancer Res 2009; 15: 3143-3149.

27 Takeuchi K, Choi YL, Soda M, et al. Multiplex reverse transcription-PCR screening for EML4-ALK fusion transcripts. Clin Cancer Res 2008; 14: 6618-6624.

28 Inamura K, Takeuchi K, Togashi Y, et al. EML4-ALK fusion is linked to histological characteristics in a subset of lung cancers. J Thorac Oncol 2008; 3: 13-17. 